\title{
O TRIUNFO DA MICRO-HISTÓRIA
}

Petrônio José Domingues'

FAUSTO, Boris. O crime do restaurante chinês: carnaval, futebol e justiça na São Paulo dos anos 30. São Paulo: Companhia das Letras, 2009.

A historiografia brasileira é dinâmica e mutante, adaptando-se dialeticamente a cada contexto histórico. A crise do marxismo e o sepultamento dos referenciais estruturalistas, de um lado, e a descrença na razão, as retóricas pósmodernistas, a ascensão dos movimentos específicos (como o das mulheres, dos negros, dos gays, dos índios, dos ambientalistas) e a emergência do neoliberalismo, de outro, levaram milhares de pessoas a se desencantarem com as grandes ideologias; a abandonarem a perspectiva de transformações sistêmicas na sociedade. Este novo cenário histórico se refletiu na prática historiográfica, contribuindo para redefinir os pressupostos teórico-metodológicos, os recortes temáticos e o uso das fontes. Novas abordagens, novos problemas e novos objetos entraram em pauta. Se, no passado, as interpretações predominantes tinham a ambição de produzir uma história total, hoje essa ambição foi praticamente descartada. De forma notável, as abordagens macros e generalizantes perdem cada vez mais espaço para as incursões micros, centradas em questões específicas. É neste novo cenário historiográfico que se insere o livro $O$ crime do restaurante chinês: carnaval, futebol e justiça na São Paulo dos anos 30, de Boris Fausto, que ora será resenhado. Publicado no primeiro semestre de 2009, o livro foi acolhido com entusiasmo pela mídia e pelo mercado editorial, chegando a comparecer às listas dos livros mais vendidos de não-ficção. A acolhida do mundo acadêmico não tem sido menos positiva.

Mas do que trata a obra? No dia 2 de março de 1938, em plena QuartaFeira de Cinzas, a cidade de São Paulo amanheceu com a notícia de um crime que abalou a opinião pública. Em um restaurante chinês, da rua Wenceslau Braz, número 13, no centro da cidade, quatro pessoas foram cruelmente assassinadas. Duas delas, o lituano José Kulikevicius e o brasileiro Severino Lindolfo Rocha, eram funcionários do restaurante e foram abatidos depois de terem recebidos vários golpes de um grosso cilindro de madeira. Já as duas outras pessoas, tratavam-se do casal de proprietários do estabelecimento. Ele - Ho-Fung, um imi-

' Doutor em História (USP); Professor Adjunto da Universidade Federal de Sergipe. E-mail: pjdomingues@yahoo.com.br 
grante chinês - foi violentamente espancado, sofreu várias fraturas na cabeça e, por fim, morreu asfixiado por um laço, apertado em torno do pescoço. Ela Maria Akiau, uma brasileira, filha de chineses - morrera por último, por esganadura, com um laço de tecido fortemente apertado, também no pescoço. A cena do crime foi macabra e, quando a polícia chegou ao restaurante, pela manhã, encontrou os corpos estendidos, desfigurados, muito sangue e um ambiente sinistro, ambiente que lembrava mais um filme de terror. É justamente a história dessa chacina, que teve grande repercussão na época, o tema do livro de Boris Fausto.

Quem teriam sido os assassinos que, movidos por uma mente perversa e insana, teriam dividido a tarefa de liquidar as vítimas? A autoria do crime do restaurante chinês ficou envolta num clima de suspense, de modo que os rádios, os jornais e as pessoas nos locais de trabalho, nas escolas, nas ruas, nos pontos dos bondes, nas esquinas, nos bares discutiam, rediscutiam, especulavam, até que a política, depois de investigar algumas pessoas suspeitas, prendeu Arias Oliveira. Tudo depunha contra Arias: era do interior paulista - proveniente de Franca -, pobre, estava desempregado e passava fome por ocasião da chacina. Além disso, aquele jovem de 22 anos, que trabalhara no restaurante por dezesseis dias e conquistara a confiança do proprietário, teria dormido no local do crime e supostamente sabia onde Ho-Fung guardava o dinheiro no cofre. Por fim, e talvez o mais comprometedor, o principal acusado era um negro, numa época em que ainda estavam vivas no imaginário social as teorias do racismo científico. Submetido pelos peritos a uma série de testes que compunha a chamada análise antropopsiquiátrica, no campo da criminologia, Arias foi considerado assassino, tese que foi reforçada com sua confissão.

Terminado o inquérito policial, o processo passou do domínio policial para o da Justiça. É neste instante que entra em cena Paulo Lauro, o advogado de defesa. Contratado pela União Negra Brasileira - uma organização que lutava contra a discriminação racial e pela elevação moral, política e social dos "homens de cor” -, Lauro demonstrou competência em defesa de seu cliente. Isto não impediu que Arias, mesmo voltando atrás na confissão, tivesse ido a julgamento no Tribunal do Júri. Muitos davam como certa a sentença condenatória do acusado. Depois de muita tensão, apreensão e morosidade, num julgamento que foi acompanhado de perto por muitas pessoas, saiu o veredicto: Arias de Oliveira foi declarado inocente, por maioria dos votos (quatro contra três). Arias ganhara a batalha judicial, mas não a guerra, já que o promotor público entrou com recurso. Resultado: um novo julgamento no Tribunal do Júri e, mais uma vez, o acusado foi absolvido. Como a legislação permitia, a Promotoria recorreu à última instância, o Tribunal de Apelação, e, por incrível que pareça, os desembargadores, por maioria 
dos votos (dois contra um), mantiveram a sentença absolutória do réu. Emocionado, Arias de Oliveira finalmente era posto em liberdade em agosto de 1942, quase quatro anos depois do início de todo aquele drama.

Talvez o leitor dessa resenha deva estar se perguntando: será que o livro de Boris Fausto se restringe a narrar a história de um crime? Não, como uma boa pesquisa de micro-história, o episódio do crime - o eixo da narrativa - serve como plataforma de salto para o autor mergulhar em cenários e contextos mais amplos. Por meio de um evento, com seus múltiplos desdobramentos, o leitor é conduzido a conhecer aspectos das novas tecnologias, da urbanização, da modernização, do cosmopolitismo e do cotidiano da paulicéia desvairada nas primeiras décadas do século XX. Mais do que terra das oportunidades e realizações, São Paulo era a terra das esperanças, onde imigrantes de várias nacionalidades e migrantes do interior e de outras unidades da Federação lutavam por um lugar ao sol. O autor dá uma atenção especial para o carnaval e o futebol - duas paixões que mobilizavam a atenção de todos, ricos e pobres, brancos e negros, estrangeiros e nacionais -, além de abordar o funcionamento do aparelho judiciário, com a estrutura da polícia científica e investigativa.

Do ponto de vista metodológico, a pesquisa reúne outros ingredientes da micro-história, a saber: escolha de um personagem anônimo; redução da escala de observação, com a exploração de um objeto que passaria despercebido numa abordagem generalizante; descrição densa e aprofundada, com a procura das relações de significados e interpretações possíveis e trabalho exaustivo envolvendo pesquisa de arquivo. "A micro-história”, argumenta Giovanni Levi, “tenta não sacrificar o conhecimento dos elementos individuais a uma generalização mais ampla, e de fato essa metodologia acentua as vidas e os acontecimentos individuais". ${ }^{2}$ É justamente isso que Boris Fausto busca aplicar em sua pesquisa: tomar um caso particular - a da absolvição do negro Arias de Oliveira, a despeito do manto do racismo -, como específico e individual, sem diluí-lo nos casos típicos. Só assim Fausto consegue fugir das explicações corriqueiras que costumam rotular, aprioristicamente, a Justiça e a "classe dominante" de racistas:

Um dos aspectos mais significativo do caso [de absolvição de Arias de Oliveira] é que este não constitui mais um exemplo tautológico da pura e simples "dominação da classe dominante”, potencializada pelo preconceito racial. Tanto a existência incontestável da dominação social quanto o preconceito de raça são caracterizações genéricas necessárias, mas que pouco nos dizem sobre suas formas e seus matizes, em particular quanto se trilha o caminho da micro-história. ${ }^{3}$ 
O crime do restaurante chinês trás a baila a discussão sobre o racismo em São Paulo na década de 1930, uma temática relevante, que vem despertando de forma crescente a atenção dos historiadores no Brasil, porém, como adverte Boris Fausto no início do livro, "se o leitor não quiser se deter na questão da relevância, quem sabe, mergulhando na leitura, encontrará o prazer da leitura de uma boa história”. De fato, a narrativa - outro preceito da micro-história - é um dos pontos altos da pesquisa. Seu estilo de narrativa é fluente, envolvente, especulativo e baseado em elementos da literatura, com direito a suspense e revelações surpreendentes, muitas imagens de época, “etnografias” minuciosas de cenários, capítulos curtos, poucas notas de final de página, mínimas citações de outros autores etc. Nesse tipo de narrativa, as motivações pessoais do pesquisador fazem parte integrante do texto. Fausto conta que, em 1938, era criança e o crime do restaurante chinês causou-lhe forte impressão: as imagens dos corpos dilacerados da chacina estampadas nos jornais, os comentários sorrateiros que ouvia em fragmentos em casa e nas ruas lhe provocaram pesadelos e assombrações noturnas. Diante disso, a pesquisa foi uma maneira de o autor exumar os fantasmas que, por décadas, jazeram nos recônditos de sua memória.

O crime do restaurante chinês é uma obra sintomática dos caminhos pelos quais vêm atravessando a produção historiográfica. Boris Fausto se notabilizou com a publicação do livro A revolução de 1930: historiografia e história, em 1972. De lá para cá, publicou sobre o movimento operário, a criminalidade, a imigração no início do século XX e até mesmo Getúlio Vargas. Depois, portanto, de ter publicado uma copiosa obra, quase sempre seguindo os ditames das abordagens generalizantes, e ter alfinetado "os estudos demasiado micro, cuja relevância não se percebe", ${ }^{4}$ o pesquisador paulista se "rendeu” à proposta da micro-história. Mas esta metamorfose não é negativa; pelo contrário, demonstra a capacidade de Fausto de se renovar e se atualizar ante os debates candentes da historiografia contemporânea.

\section{NOTAS}

${ }^{2}$ LEVI, Giovanni. "Sobre a micro-história". In: BURKE, Peter. A escrita da história: novas perspectivas. São Paulo: Editora da UNESP, 1992, p. 158.

${ }^{3}$ FAUSTO, Boris. O crime do restaurante chinês: carnaval, futebol e justiça na São Paulo dos anos 30. São Paulo: Companhia das Letras, 2009, p. 214.

${ }^{4}$ MORAES, José Geraldo Vinci de; REGO, José Márcio (orgs.). Conversas com historiadores brasileiros. São Paulo: Editora 34, 2002, p. I 10. 